\title{
Germinação e crescimento inicial de variedades de feijão caupi submetidas a diferentes concentrações salinas
}

\section{Germination and initial growth of cowpea cultivars under salinity stress}

\author{
Daniela Siqueira Coelho ${ }^{1}$, José Aliçandro Bezerra da Silva $^{2 *}$, Russaika Lírio Nascimento ${ }^{3}$, Josenara Daiane de Souza Costa ${ }^{4}$, \\ Tales Xavier Seabra ${ }^{5}$
}

Resumo: A utilização de variedades tolerantes ao estresse salino tem sido essencial para o estabelecimento de culturas comerciais em áreas salinas. Objetivou-se avaliar a germinação e o crescimento inicial de plântulas de quatro variedades de feijão caupi submetidas a diferentes níveis de estresse salino. As sementes das cultivares BRS Tapaihum, BRS Pujante, BRS Acauã e BRS Marataoã foram semeadas em espumas, dispostas em bandejas e umedecidas com as seguintes concentrações de $\mathrm{NaCl}$ : 0, 50, 100, 150 e $200 \mathrm{mM}$. Foram determinadas as variáveis: percentual de germinação, índice de velocidade de emergência, tempo médio, frequência relativa de germinação, comprimento da parte aérea e teor de água das plântulas. As variedades de feijão caupi apresentaram perda na capacidade germinativa a partir da concentração de $50 \mathrm{mM}$ de $\mathrm{NaCl}$. Também foi verificado que a incidência da salinidade promoveu uma diminuição da velocidade com que as variedades realizaram seus eventos bioquímicos, fisiológicos, morfogênicos necessários ao processo de germinação e formação das novas plantas.

Palavras-chave: Vigna unguiculata (L.) Walp; Tolerância; Emergência; Frequência relativa; Estresse.

\begin{abstract}
The use of varieties tolerant to salinity stress conditions has been essential for the crops establishment in are asthat experience with this problem. The aim of this study was to evaluate the germination process and early growth of seedlings of four varieties of cowpea under different levels of salinity. The seeds of BRS Tapaihum, BRS Pujante, BRS Acauã and BRS Marataoã were sown in foam, arranged in tray sand watered with the following $\mathrm{NaCl}$ concentrations: 0,50, 100, 150 and 200mM. The analized variables were Percentage of Germination, Emergence Speed Index, mean time, Relative Germination frequency, shoot length and water content of seedling. The cowpea varieties showed loss of germination capacity from $50 \mathrm{mM}$ $\mathrm{NaCl}$ concentration. It was also verified that the salinity incidence promoted a decrease of the speed with which the varieties realized their biochemical, physiological, morphogenic events necessary to the process of germination and formation of the new plants.
\end{abstract}

Key words: Vigna unguiculata(L.) Walp; Tolerance; Emergence; Relative frequency; Stress.

\footnotetext{
*Autor para correspondência

Recebido para publicação em 27/08/2016; aprovado em 16/06/2017

${ }^{1}$ Doutora em Ciências do Solo pela Universidade Federal Rural de Pernambuco, Recife-PE; (87) 99952-8331, daniela.coelho@ hotmail.com.br

${ }^{2}$ Doutor em Biologia Vegetal, Professor Associado do Colegiado de Engenharia Agrícola e Ambiental, Universidade Federal do Vale do São Francisco,

Juazeiro-BA, jose.alicandro@univasf.edu.br

${ }^{3}$ Mestra em Engenharia Agrícola pela Universidade Federal do Vale do São Francisco, Juazeiro-BA, nrussaika@gmail.com

${ }^{4}$ Doutoranda em Engenharia Agrícola pela Universidade Federal de Campina Grande, Campina Grande-PB, josenara.costa@gmail.com

${ }^{5}$ Graduando em Engenharia Agrícola e Ambiental, Universidade Federal do Vale do São Francisco, Juazeiro-BA, tales.xs@ hotmail.com
} 


\section{INTRODUÇÃO}

A salinidade é um problema que atinge cerca de 50 dos 250 milhões de hectares de área irrigada do globo terrestre, sendo que milhões de hectares são abandonados anualmente em virtude desse problema (FAO, 2005). Em regiões áridas e semiáridas, a salinidade ocorre principalmente pelas elevadas taxas de evapotranspiração e baixa precipitação promovendo a ascensão de sais para a superfície do solo (MEDEIROS et al., 2010). Nessas regiões, essse problema ainda é agravado pelo uso de água de baixa qualidade associada a técnicas inadequadas de manejo (SILVA et al., 2009).

Com o aumento da concentração de sais na solução do solo, as plantas são submetidas a diferentes condições de estresse, causadas pela redução do potencial osmótico do solo, toxicidade de íons específicos e pela interferência dos sais em processos fisiológicos (DIAS; BLANCO, 2010). O efeito do excesso de sais sobre as plantas ocorre desde o seu processo de germinação, causando estresse osmótico e toxicidade às sementes (KHAN; PANDA, 2008), sendo este último ocasionado principalmente pelo acúmulo em excesso de íons $\mathrm{Na}^{+}$e $\mathrm{Cl}^{-}$(ESTEVES; SUZUKI, 2008).

Em caso de estresse osmótico, a embebição é comprometida pela redução do potencial hídrico e o crescimento da plântula é afetado pela diminuição da expansão e do alongamento celular (MOTERLE et al., 2008). Já o acúmulo de íons como $\mathrm{Na}^{+}$e $\mathrm{Cl}^{-}$em concentrações tóxicas podem afetar processos fisiológicos e metabólicos dos tecidos embrionários. Segundo Klafke (2008), o excesso de $\mathrm{Na}^{+}$e $\mathrm{Cl}^{-}$no protoplasma interfere nos níveis de poliaminas; putrescina e espermidina no meio celular, que são responsáveis pela ativação de diversas enzimas do processo de germinação bem como pela regulação dos processos de divisão e diferenciação celular, atividade de enzimas e a distribuição de nutrientes de reserva (DANTAS et al., 2011).

Várias espécies em condições de estresse salino alteram sensivelmente seu padrão de germinação, crescimento e desenvolvimento das plantas. Cruz et al. (2016), avaliando estresse salino na qualidade fisiológica de sementes de Cryptostegia madagascariensis verificaram que o aumento da salinidade no substrato de cultivo reduziu de forma significativa o crescimento das plântulas, reduzindo a germinação das sementes, o comprimento e produção de matéria seca de raízes. Já Ferreira et al. (2013), também avaliando o efeito da salinidade sobre processo germinativo e vigor de sementes de Cedrela odorata verificaram que os níveis entre 75 e $100 \mathrm{mM}$ de $\mathrm{NaCl}, \mathrm{KCl}$ e $\mathrm{CaCl}_{2}$ interferiram de forma extremamente negativa em vários atributos relacionados a germinação e crescimento inicial das plântulas, como velocidade de emergência, comprimento da raiz, comprimento do hipocótilo e massa seca das plântulas.

De acordo com Deuner et al. (2011) avaliando o efeito da salinidade sobre viabilidade e atividade antioxidante de sementes de genótipos de feijão-miúdo verificaram o aumento do nível de salinidade até $200 \mathrm{mM}$ de $\mathrm{NaCl}$ reduz para níveis com capacidade de anular a ativação do processo de germinação e emergência das plântulas, entretanto, nas concentrações intermediárias de sal, as enzimas antioxidantes apresentam atividade eficiente na proteção contra o estresse salino, porém, este efeito não é mantido para a maior dose testada.

Diante de todos os problemas que ocorrem com o aumento da salinidade em áreas agricultáveis no mundo e seus efeitos negativos sobre o crescimento e desenvolvimento das plantas a busca por espécies e variedades resistentes é de extrema importância.

Para as espécies resistirem às condições de estresse salino é necessário que ocorra a ativação de mecanismos que proporcionem alterações no metabolismo celular. Entre os mecanismos mais eficientes destaca-se a capacidade das células em acumular íons nos vacúolos, ou ainda solutos orgânicos de baixo peso molecular capazes de manter a absorção de água e a turgescência celular (MUNNS; TESTER, 2008). Essas estratégias refletem diretamente no grau de tolerância das espécies à salinidade, permitindo que ocorra o processo de germinação e emergência das plântulas refletindo nos estádios subsequentes de crescimento e desenvolvimento das plantas.

Em função da resistência intrínseca a cultura e aos estudos de melhoramento genético têm sido selecionadas variedades de feijão caupi [(Vigna unguiculata (L.) Walp.], com grau moderado de tolerância à salinidade, contribuindo desta forma para minimizar os problemas decorrentes da salinização (LIMA et al., 2007).

No entanto, as variedades de feijão caupi quando submetidas às diferentes condições de salinidade apresentam variações quanto às respostas fisiológicas como alteração do acúmulo de matéria seca da parte aérea e relação parte aérea/raiz, germinação e o vigor das sementes, crescimento de plântulas, bem como a síntese de proteínas totais (DANTAS et al., 2002; DANTAS et al., 2005), tornando de extrema importância o estudo sobre resistência à salinidade, como subsídio para seleção de variedades mais resistentes.

Sendo assim, objetivou-se avaliar o processo de germinação e o crescimento inicial de plântulas de quatro variedades de feijão caupi submetidas a diferentes concentrações salinas.

\section{MATERIAL E MÉTODOS}

O experimento foi conduzido no Laboratório de Citologia e Fisiologia Vegetal da Universidade Federal do Vale do São Francisco, Campus Juazeiro (BA), utilizando sementes de quatro variedades de feijão caupi: BRS Tapaihum, BRS Pujante, BRS Acauã e BRS Marataoã.

As sementes foram dispostas em esponjas de polietileno com dimensões de 46,7 x 30,0 x 2,0 cm, colocadas em bandejas de plástico $(47,0$ x 32,0 x 8,0 cm). Para possibilitar melhor acomodação das sementes, foram feitas perfurações na esponja aumentando a superfície de contato entre a semente e a solução utilizada. Em seguida, as esponjas de cada bandeja foram umedecidas com diferentes concentrações de solução de cloreto de sódio $(\mathrm{NaCl})$ : 0 (água deionizada); 50; $100 ; 150$ e $200 \mathrm{mM}$.

O delineamento experimental utilizado foi em blocos casualizados dispostos em arranjo fatorial 4 x 5, considerando quatro variedades e cinco soluções de cloreto de sódio. Para cada tratamento foram utilizadas quatro repetições, cada uma composta por 30 sementes.

Antes da semeadura, as sementes foram imersas por trinta segundos em solução de Captan diluída na proporção 1:5, sendo posteriormente colocadas para secar a sombra. Após a secagem, as sementes foram dispostas nas esponjas sobre as bandejas e colocadas em sala de crescimento, no escuro, à temperatura média de $25^{\circ} \mathrm{C}$. 
Após 24 horas, foi iniciada a contagem de germinação, sendo realizada diariamente até o $10^{\circ}$ dia após a semeadura (DAS). Através das fórmulas propostas por Labouriau e Valadares (1976) e Maguire (1962) foram calculados o percentual de germinação, índice de velocidade de emergência (IVE), tempo médio de germinação (Tm) e a frequência relativa de germinação (Fr).

A partir do $11^{\circ}$ DAS, em cada bandeja, foram selecionadas aleatoriamente oito sementes de cada variedade para avaliação do comprimento da parte aérea e do teor de água das plântulas, estimado a partir dos valores de massa inicial e massa final das plântulas germinadas.

A massa fresca foi obtida a partir da pesagem das plântulas selecionadas, sendo o material colocado posteriormente em sacos de papel devidamente identificados e levados para secar em estufa a uma temperatura de $60^{\circ} \mathrm{C}$ por um período de 72 horas, para a obtenção da massa seca.

Os resultados foram submetidos à análise de variância realizando o teste de Tukey $(\mathrm{p}<0,05)$ para comparação entre variedades e ajustando modelos de regressão para os níveis de salinidade.

\section{RESULTADOS E DISCUSSÃO}

Não houve interação significativa entre as variedades e os níveis de salinidade avaliados. Dessa forma, os fatores foram avaliados de forma independente.

O percentual de germinação das sementes para todas as variedades foi próximo de $100 \%$ para a concentração de 0 $\mathrm{mM}$, sendo observado decréscimo gradual à medida que a concentração da solução salina aumentou (Figura 1).

Figura 1. Percentual de germinação de plantas de feijão caupi, independente da variedade, submetidas a diferentes concentrações de $\mathrm{NaCl}$. Regressão significativa $(\mathrm{p}<0,05)$.

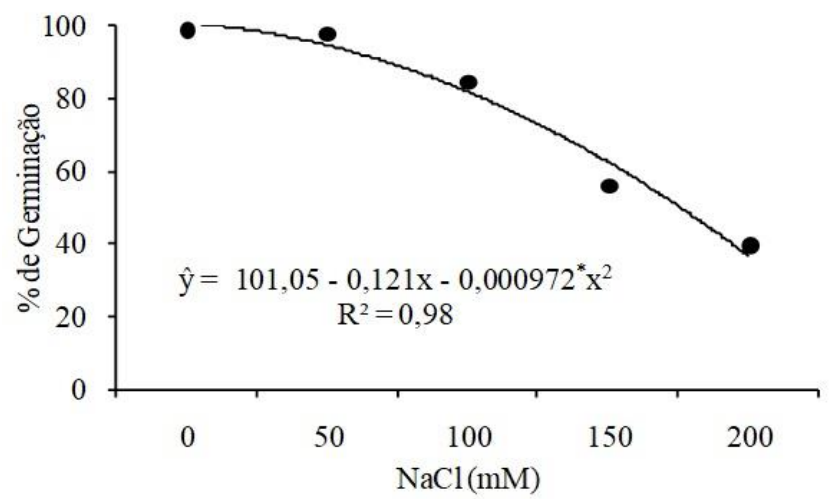

Independente da variedade avaliada foi observado redução linear no índice de velocidade de emergência (IVE) com o aumento da concentração da solução salina (Figura 2A). Entretanto, o tempo médio de germinação cresceu linearmente sob essas condições (Figura 2B). Trabalhos realizados avaliando a germinação, emergência e crescimento inicial de plantas através do uso de sementes, de diferentes espécies de feijão, submetidas a níveis crescentes de sais, mostraram tendências semelhantes de quedas para os dois parâmetros em função do aumento dos níveis de salinidade (DEUNER et al., 2011; MAIA et al., 2012; DANTAS et al., 2005)
Figura 2. Índice de velocidade de emergência - IVE (A) e Tempo médio de germinação - Tm (B) de sementes de plântulas de feijão caupi, independente da variedade, submetidas a diferentes concentrações de $\mathrm{NaCl}$. ${ }^{* *}$ Regressão significativa $(\mathrm{p}<0,01)$.
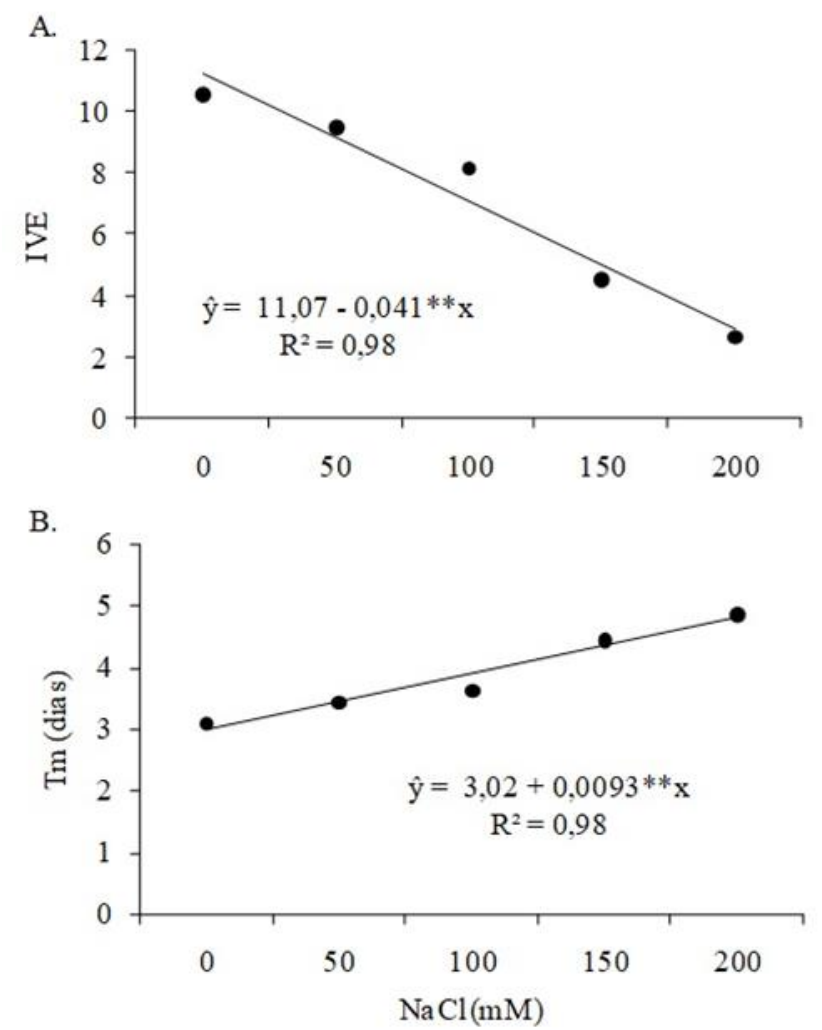

Essa queda gradual no percentual germinativo e nos valores de IVE observadas em todas as variedades pode estar relacionada com a redução do potencial osmótico da solução em contato com as sementes. Segundo Tobe et al. (2000), o efeito osmótico ocasionado pelo excesso de sais, provoca a conhecida "seca fisiológica", que é um processo resultante da elevação da concentração de íons no protoplasma. O aumento da concentração de íons $\mathrm{Na}^{+}$e $\mathrm{Cl}^{-}$reduz a velocidade de absorção de água pelas sementes e consequentemente interfere no metabolismo, divisão, alongamento e diferenciação celular (FANTI; PEREZ, 2004).

Segundo Larré et al. (2011), os valores de IVE representam o efeito direto dos sais na redução do vigor das sementes uma vez que o mesmo está envolvido com o atraso na ocorrência da germinação. Para Bertagnolli et al. (2004), a perda da capacidade de germinação, emergência e posterior crescimento da plantas estão relacionadas com o processo de deterioração da semente, no qual ocorre alteração do metabolismo, principalmente pela redução da atividade de várias enzimas que apresentam susceptibilidade específica à salinidade.

A redução do vigor das sementes submetidas a soluções de alta concentração salina também foi observada em couve (LOPES; MACEDO, 2008), pinhão manso (ANDREOSOUZA et al., 2010), milho-pipoca (MOTERLE et al., 2006), melancia (TORRES, 2007), e até em variedades consideradas moderadamente tolerantes ou tolerantes segundo Dias e Blanco (2010), como as sementes de sorgo forrageiro (OLIVEIRA; GOMES-FILHO, 2009), cártamo (DANTAS et al., 2011) e cevada (SILVA et al., 2007), demonstrando que o efeito osmótico, ocasionado pelo acúmulo de sais na solução em contato com a semente, pode reduzir o processo de 
embebição mesmo em espécies que apresentam mecanismos de ajustamento mais eficientes para resistir às condições salinas.

Quanto à frequência relativa de germinação (Fr), foi observado que a germinação das sementes de todas as variedades ocorreu de forma concentrada nos primeiros cinco dias após a semeadura para as concentrações até $100 \mathrm{mM}$ de $\mathrm{NaCl}$ (Figura 3). Para as cultivares BRS Tapaihum e BRS
Acauã a distribuição do polígono de frequência foi do tipo unimodal, pois a frequência de germinação está concentrada em um único dia. Para as concentrações de 150 e 200 mM, o período de germinação foi variado ocorrendo distribuição polimodal da germinação ao longo do período de avaliação, o que demonstra a perda da capacidade germinativa das sementes sob o efeito osmótico e tóxico dos íons, reduzindo assim a velocidade de germinação.

Figura 3. Frequência relativa de germinação (Fr) de sementes de quatro variedades de feijão caupi BRS Pujante, BRS Marataoã, BRS Tabaihum e BRS Acauã, submetidas a concentrações de 0 (A), 50 (B), 100 (C), 150 (D) e 200 mM de NaCl (E).
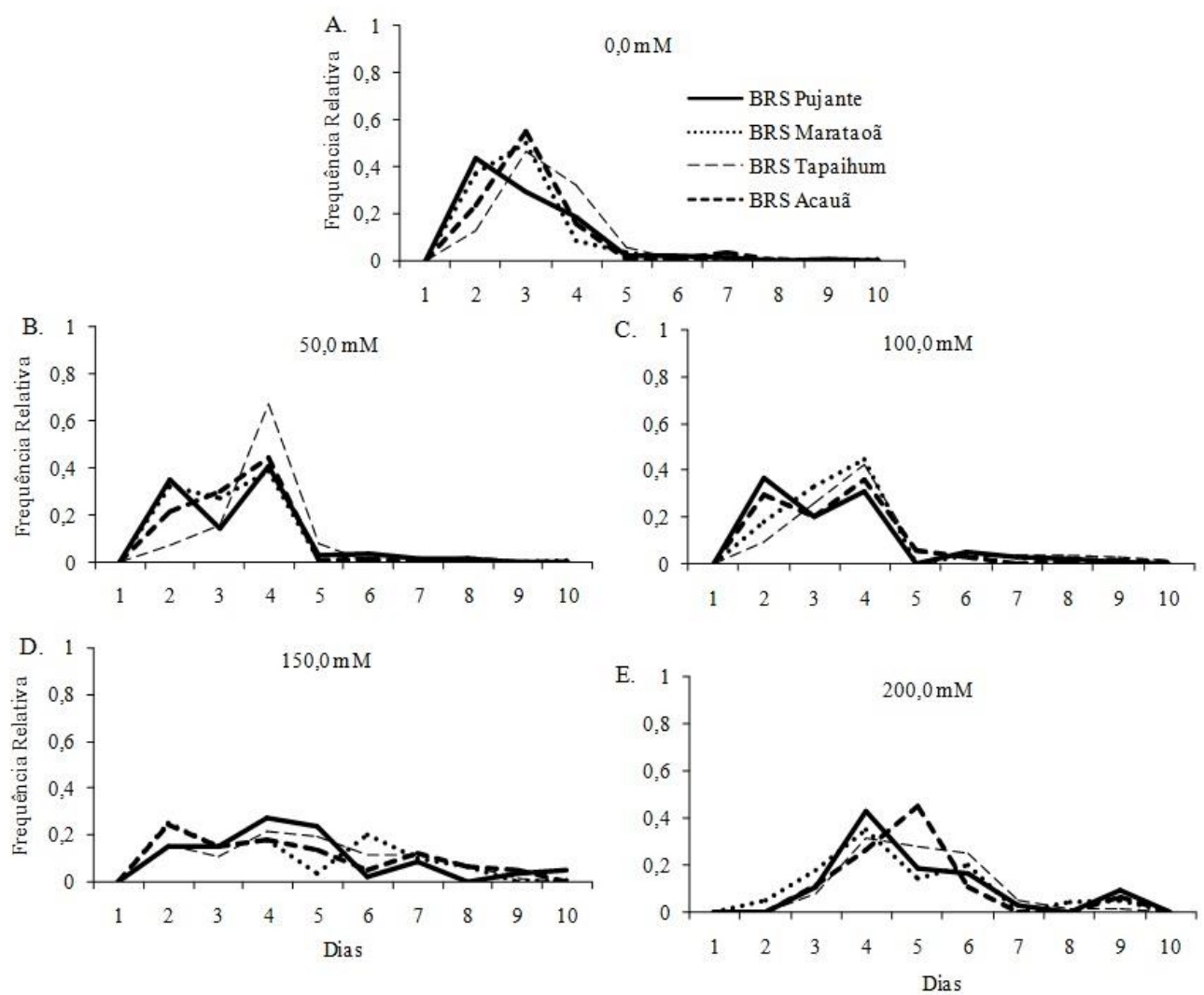

Para a maior concentração salina, as sementes da variedade BRS Pujante apresentaram maiores picos de germinação, concentrando-se nos primeiros cinco dias após a semeadura. Características heterogêneas de frequência relativa com tendência ao comportamento polimodal à medida que ocorreu aumento na concentração salina também foram observadas em sementes de algarobeira (PEREZ; MORAES, 1994), leucena (CAVALCANTE; PERES, 1995) e camapu (SOUZA et al., 2011).

Em relação à avaliação do crescimento inicial das plântulas, verificou-se que as variedades de feijão caupi apresentaram elevada sensibilidade a ambientes salinos, interferindo diretamente na formação da sua parte aérea. Para o método utilizado, apenas foi possível observar formação de parte aérea em plântulas submetidas à água deionizada (0 $\mathrm{mM}$ ), para a qual, não foram constatadas diferenças significativas entre as variedades quanto ao comprimento da parte aérea das plântulas (Figura 4).

Figura 4. Comprimento da parte aérea $(\mathrm{cm})$ de plântulas de quatro variedades de feijão caupi, para o tratamento controle (0 mM). Colunas de mesma letra não se diferenciam pelo teste f a 5\% de probabilidade. Coeficiente de Variação - C.V. $-49,92 \%$.

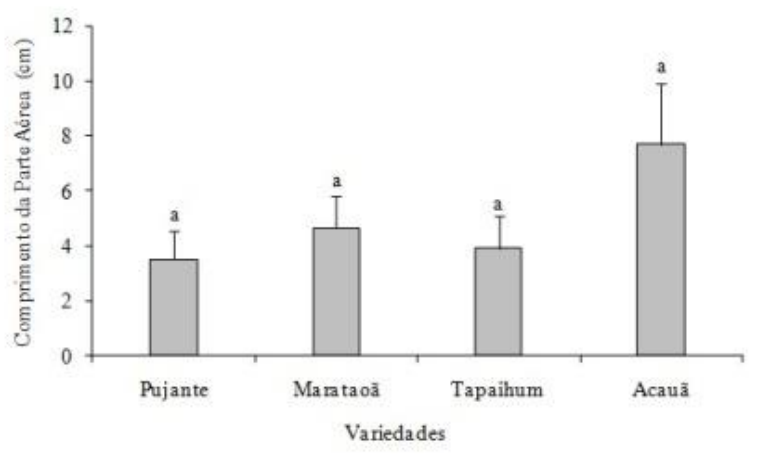

Em relação ao teor de água das plântulas, independente da variedade avaliada, foi observada redução de até 54\%, ocorrendo para plântulas submetidas a uma solução estimada em 146,6 mM de $\mathrm{NaCl}$. 
Figura 5. Teor de água das plântulas (TA\%) de feijão caupi, independente da variedade, submetidas a diferentes concentrações de $\mathrm{NaCl} .{ }^{* *}$ Regressão significativa $(\mathrm{p}<0,01)$.

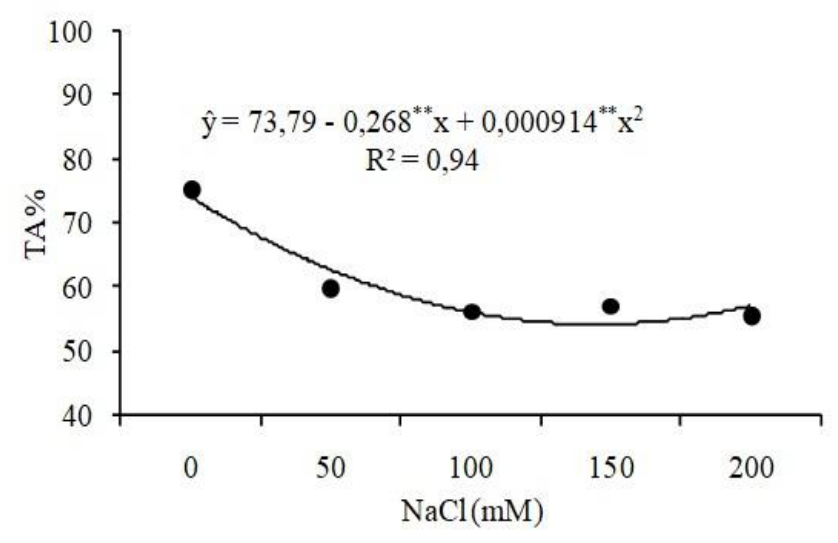

Independente do nível de salinidade, as variedades não apresentaram diferenças no percentual de germinação e no teor de água das plântulas (Tabela 1). Apenas é possível afirmar que a BRS Marataoã apresentou maior velocidade de emergência e menor tempo de germinação quando comparado à BRS Tapaihum.

Tabela 1. Percentual de germinação, índice de velocidade de emergência (IVE), tempo médio de germinação (Tm) e Teor de água das plântulas (TA\%) das variedades de feijão caupiindependente do nível de salinidade imposto.

\begin{tabular}{ccccc}
\hline & \% germinação & IVE & Tm & TA\% \\
\hline BRS Pujante & $71,50 \mathrm{a}^{*}$ & $7,13 \mathrm{ab}$ & $3,85 \mathrm{ab}$ & $59,54 \mathrm{a}$ \\
BRS Marataoã & $82,83 \mathrm{a}$ & $8,10 \mathrm{a}$ & $3,70 \mathrm{~b}$ & $63,25 \mathrm{a}$ \\
BRS Tapaihum & $74,50 \mathrm{a}$ & $6,16 \mathrm{~b}$ & $4,24 \mathrm{a}$ & $59,05 \mathrm{a}$ \\
BRS Acauã & $72,67 \mathrm{a}$ & $7,00 \mathrm{ab}$ & $3,86 \mathrm{ab}$ & $61,28 \mathrm{a}$ \\
\hline
\end{tabular}

variedades com mesma letra não diferem entre si pelo teste e Tukey $(\mathrm{p}<0.05)$.

Dessa forma, é possível inferir que de alguma forma a germinação e o crescimento inicial das plântulas foram afetados, indicando o provável efeito negativo dos íons $\mathrm{Na}^{+} \mathrm{e}$ $\mathrm{Cl}^{-}$sob a produção e ativação enzimática, divisão e diferenciação celular.

\section{CONCLUSÕES}

As variedades avaliadas de feijão caupi apresentaram baixa tolerância a salinidade, apresentando a partir da concentração de $50 \mathrm{mM}$ de $\mathrm{NaCl}$ limitações para o processo de germinação e crescimento inicial das plântulas.

\section{REFERÊNCIAS}

ANDREO-SOUZA, Y.; PEREIRA, A. L.; SILVA, F. F. S.; REIS, R. C. R.; EVANGELISTA, M. R. V. CASTRO, R. D.; DANTAS, B. F. Efeito da salinidade na germinação de sementes e no crescimento inicial de mudas de pinhão-manso. Revista Brasileira de Sementes, Londrina, v.32, n.2, p.83-92, 2010 .
BERTAGNOLLI, C. M.; CUNHA, C. S. M.; MENEZES, S. M.; MORAES, D. M.; LOPES, N. F.; ABREU, C. M. Qualidade fisiológica e composição química de sementes de soja submetidas ao estresse salino. Revista Brasileira de Agrociência, Pelotas, v.10, n.3, p.287-291, 2004.

CAVAlCANTE, A. M. B.; PEREZ, S. C. J. G. A. Efeitos dos estresses hídrico e salino sobre a germinação de sementes de Leucaena leucocephala (Lam.) de Wit. Pesquisa Agropecuária Brasileira, Brasília, v.30, n.2, p.281-289, 1995.

CRUZ, F. R. S.; ANDRADE, L. A.; ALVES, E. U. Estresse salino na qualidade fisiológica de sementes de Cryptostegia madagascariensis Bojer ex Decne. Ciência Florestal, Santa Maria, v.26, n.4, p.1189-1199, 2016.

DANTAS, B. F.; RIBEIRO, L. S.; ARAGÃO, C. A. Physiological response of cowpea seeds to salinity stress. Revista Brasileira de Sementes, Londrina, v.27, n.1, p.144148, 2005.

DANTAS, C. V. S.; SILVA, I. V.; PEREIRA, G. M.; MAIA, J. M.; LIMA, J. P. M. S.; MACEDO, C. E. C. Influência da salinidade e déficit hídrico na germinação de sementes de Carthamus tinctorius L. Revista Brasileira de Sementes, Londrina, v.33, n.3, p.574-582, 2011.

DANTAS, J. P.; MARINHO, F. J. L.; FERREIRA, M. M. M.; AMORIM, M. S. N.; ANDRADE, S. I. O.; SALES, A. L. Avaliação de genótipos de caupi sob salinidade. Revista Brasileira de Engenharia Agrícola e Ambiental, Campina Grande, v.6, n.3, p.425-430, 2002.

DEUNER, C.; MAIA, M. S.; DEUNER, S.; ALMEDIDA, S.; MENEGHELLO, G. E. Viabilidade e atividade antioxidante de sementes de genótipos de feijão-miúdo submetidos ao estresse salino. Revista Brasileira de Sementes, Londrina, v.33, n.4, p.711-720, 2011.

DIAS, N. S; BLANCO, F. F. Efeitos dos sais no solo e na planta. In: Gheyi, H. R.; Dias, N. S.; Lacerda, C. F. Manejo da salinidade na agricultura: Estudos básicos e aplicados. Fortaleza: INCT Sal, 2010. p.130-141.

ESTEVES, B. S.; SUZUKI, M. S. Efeito da salinidade sobre as plantas. Oecologia Australis, Rio de Janeiro, v.12, n.4, p.662-679, 2008.

FANTI, S. C.; PEREZ, J. G. A. Processo germinativo de sementes de paineira sob estresses hídrico e salino. Pesquisa Agropecuária Brasileira, Brasilia, v.39, n.9, p.903-909, 2004.

FAO. Food and Agricultture Organization of the United Nations.Global network on integrated soil management for sustainable use of salt-affected soils.Rome, FAO Land and Plant Nutrition Management Service. Disponível em: <www.fao.org/ag/AGL/agll/spush/intro.htm>. Acessado em: 20 de dezembro de 2015.

FEREIRA, E. G. B. S.; MATOS, V. P.; SENA, L. H. M.; OLIVEIRA, R. G.; FIGUEIREDO, A. G. F.; SALES, A. G. F. A. Processo germinativo e vigor de sementes de Cedrela 
odorata L. sob estresse salino. Revista Ciência Florestal, Santa Maria, v.23, n.1, p.99-105, 2013.

KHAN, M. H.; PANDA, S. K. Alterations in root lipid peroxidation and antioxidative responses in two rice cultivars under NaCl-salinity stress. Acta Physiologiae Plantarum, v.30, n.1, p.81-89, 2008.

KLAFKE, A. V. Desempenho de sementes nuas e revestidas de azevém anual (Lolium multiflorum Lam.) em condições de estresse salino. 2008, 191f. Dissertação (Mestrado em Zootecnia) - Universidade Federal do Rio Grande do Sul, Porto Alegre. 2008.

LABOURIAU, L. G.; VALADARES, M. E. B. On the germination of seeds Calotropis procera (Ait.) Ait.f. Anais da Academia Brasileira de Ciências, Rio de Janeiro, v.48, n.2, p.263-284, 1976.

LARRÉ, C. F.; MORAES, D. M.; LOPES, N. F. Qualidade fisiológica de sementes de arroz tratadas com solução salina e 24-epibrassinolídeo. Revista Brasileira de Sementes, Londrina, v.33, n.1, p.86-94, 2011.

LIMA, C. J. G. S.; OLIVEIRA, F. A.; MEDEIROS, J. F.; OLIVEIRA, M. K. T.; ALMEIDA JÚNIOR, A. B. Resposta do Feijão Caupi à salinidade da água de irrigação. Revista Verde de Agroecologia e Desenvolvimento Sustentável, Mossoró, v.2, n.2, p.79-86, 2007.

LOPES, J. C.; MACEDO, C. M. P. Germinação de sementes de couve chinesa sob influência do teor de água, substrato e estresse salino. Revista Brasileira de Sementes, Londrina, v.30, n.3, p.79-85, 2008 .

MAGUIRE, J. D. Speed of germination-aid in selection and evaluation for seedling emergence and vigor. Crop Science, Madison, v.2, n.2, p.176-177, 1962.

MAIA, J. M.; SILVA, S. L. F., VOIGT, E. L.; MACÊDO, C. E. C.; PONTE, L. F. A.; SILVEIRA, J. A. G. Atividade de enzimas antioxidantes e inibição do crescimento radicular de feijão caupi sob diferentes níveis de salinidade. Acta Botanica Brasilica, Belo Horizonte, v.26, n.2, p.342-349, 2012.

MEDEIROS, J. F.; NASCIMENTO, I. B. GHERY, H. R. Manejo do solo-água-planta em área afetadas por sais. In: GHEYI, H. R.; DIAS, N. S.; LACERDA, C. F. Manejo da salinidade na agricultura: Estudos básicos e aplicados. Fortaleza: INCT Sal, 2010. p.280-302.

MOTERLE, L. M.; LOPES, P. C.; BRACCINI, A. L.; SCAPIM, C. A. Germinação de sementes e crescimento de plântulas de cultivares de milho-pipoca submetidas ao estresse hídrico e salino. Revista Brasileira de Sementes, Londrina, v.28, n.3, p.169-176, 2006.

MOTERLE, L. M.; SCAPIM, C. A.; BRACCINI, A. L.; RODOVALHO, M. A.; BARRETO, R. R. Influência do estresse hídrico sobre o desempenho fisiológico de sementes de híbridos simples de milho-pipoca. Ciência e Agrotecnologia, Lavras, v.32, n.6, p.1810-1817, 2008.
MUNNS, R.; TESTER, M. Mechanisms of salinity tolerance. The Annual Review of Plant Biology, v.59, p.651-681, 2008.

OLIVEIRA, A. B.; GOMES-FILHO, E. Germinação e vigor de sementes de sorgo forrageiro sob estresse hídrico e salino. Revista Brasileira de Sementes, Londrina, v.31, n.3, p.4856,2009 .

PEREZ, S. C. J. G. A.; MORAES, J. A. P. V. Estresse salino no processo germinativo de algarobeira e atenuação de seus efeitos pelo uso de reguladores de crescimento. Pesquisa Agropecuária Brasileira, Brasília, v.29, n.3, p.389-396, 1994.

SILVA, R. N.; LOPES, N. F.; MORAES, D. M., PEREIRA, A. L. A.; DUARTE, G. L. Physiological quality of barley seeds submitted to saline stress. Revista Brasileira de Sementes, Londrina, v.29, n.1, p.40-44, 2007.

SILVA, S. L. F.; VOIGT, E. L.; VIÉGAS, R. A.; PAIVA, J. R.; SILVEIRA, J. A. G. Influence of rootstocks on the resistance of cashew plantlets to salt stress. Pesquisa Agropecuária Brasileira, Brasilia, v.44, n.4, p.361-367, 2009.

SOUZA, M. O.; SOUZA, C. L. M., PELACANI, C. R. Germinação de sementes osmocondicionadas e não osmocondicionadas e crescimento inicial de Physalis angulata L. (Solanaceae) em ambientes salinos. Acta Botânica Brasílica, Belo Horizonte, v.25, n.1, p.105-112, 2011.

TOBE, K.; LI, X.; OMASA, K. Seed germination and radicle growth of a halophyte, Kalidium caspicum (Chenopodiaceae). Annals of Botany, Exeter, v.85, n.3, p.391-396, 2000.

TORRES, S. B. Germinação e desenvolvimento de plântulas de melancia em função da salinidade. Revista Brasileira de Sementes, Londrina, v.29, n.3, p.77-82, 2007. 